\title{
Gastric Mucosal Atrophy Might Be Associated with the Efficacy of First-Line Therapy Using Vonoprazan for Helicobacter pylori
}

\author{
Mika Miura1, Masahiko Ohtaka1 ${ }^{*}$, Mitsuhiko Hanawa1, Naoki Shimura1, Yoshioki Yoda1, \\ Sho Suzuki² \\ ${ }^{1}$ Yamanashi Koseiren Health Care Center, Yamanashi, Japan \\ ${ }^{2}$ Division of Gastroenterology and Hepatology, Department of Medicine, Nihon University School of Medicine, Tokyo, Japan \\ Email: ^mohtaka@yamanashi.ac.jp
}

How to cite this paper: Miura, M., Ohtaka, M., Hanawa, M., Shimura, N., Yoda, Y. and Suzuki, S. (2017) Gastric Mucosal Atrophy Might Be Associated with the Efficacy of First-Line Therapy Using Vonoprazan for Helicobacter pylori. Open Journal of Gastroenterology, 7, 243-259.

https://doi.org/10.4236/ojgas.2017.79026

Received: September 7, 2017

Accepted: September 26, 2017

Published: September 29, 2017

Copyright (๑) 2017 by authors and Scientific Research Publishing Inc. This work is licensed under the Creative Commons Attribution International License (CC BY 4.0).

http://creativecommons.org/licenses/by/4.0/

\begin{abstract}
Aim: To investigate the factors related to the effect of eradication therapy with vonoprazan for Helicobacter pylori ( H. pylori). Methods: We retrospectively reviewed medical records of $H$. pylori-positive patients who received first-line (40 $\mathrm{mg}$ vonoprazan/60 $\mathrm{mg}$ lansoprazole or $20 \mathrm{mg}$ rabeprazole, $1500 \mathrm{mg}$ amoxicillin, $400 \mathrm{mg}$ clarithromycin, all $2 /$ day for 7 days $)(\mathrm{n}=4118) . H$. pylori eradication was assessed by the ${ }^{13} \mathrm{C}$-urea breath test with success defined as a result of $<2.5 \%$. Using propensity score matching, successful eradication rates were compared between two groups: those receiving vonoprazan and those receiving a proton pump inhibitor. Related factors and adverse events were investigated. Results: Successful first-line eradication rates according to ITT analysis and PP analysis, respectively, were $79.8 \%$ and $91.4 \%$ for VPZ therapy. Eradication rates using propensity matched patients $(\mathrm{n}=1053)$ who received first-line vonoprazan therapy were higher than in those using proton pump inhibitor (PPI) therapy $(92.1 \%$ vs. $79.7 \%$ in per-protocol analysis, $\mathrm{p}<$ $0.0001)$. Multivariate analysis confirmed that gastric mucosal atrophy was associated with treatment success. Conclusions: Low-dose clarithromycin triple therapy for first-line $H$. pylori eradication therapy using vonoprazan was more effective than standard triple therapy with proton pump inhibitor. Gastric mucosal atrophy was associated with treatment success.
\end{abstract}

\section{Keywords}

Vonoprazan, Eradication, Helicobacter pylori, Propensity Score Matching, Gastric Mucosal Atrophy 


\section{Introduction}

Helicobacter pylori ( H. pylori) in humans is commonly associated with gastroduodenal diseases, such as chronic gastritis, peptic ulcer diseases, mucosal-associated lymphoid tissue lymphoma, and gastric neoplasms [1] [2]. Curative treatment of $H$. pylori infection was proved to markedly reduce the rate of relapse of a variety of gastroduodenal diseases [2] [3]. In 2014, The International Agency for Research on Cancer (IARC) Working Group recommended H. pylo$r i$ eradication as a strategy for preventing gastric cancer [4]. It encouraged all countries to explore the possibility of introducing population-based $H$. pylori screening and treatment programs adjusted to local healthcare environments and needs [5].

The standard triple therapy for $H$. pylori eradication is a proton pump inhibitor (PPI), amoxicillin (AMPC), and clarithromycin (CAM) twice daily for 7 days [6]. However, the $H$. pylori eradication rate for standard triple therapy is currently less than $80 \%$ in most parts of the world [7] [8]. The main cause of this ineffectiveness may be explained by bacterial resistance to CAM [7] [8]. Several approaches were proposed to overcome these low eradication rates; either sequential therapy or concomitant therapy achieved better results than standard triple therapy [9] [10]. The latest guidelines recommend quadruple therapies comprised of PPI + AMPC + CAM + metronidazole (MNZ) or PPI + bismuth + $\mathrm{MNZ}+$ tetracycline, with all treatments given for 14 days [2] [3].

Potassium-competitive acid blockers (P-CABs) are a new class of gastric acid suppressive agents. Similar to PPIs, P-CABs inhibit gastric hydrogen/potassiumATPase but, unlike PPIs, P-CABs inhibit the enzyme in a potassium-competitive and reversible manner [11]. Vonoprazan (VPZ) is a novel orally administered member of this class. VPZ has a potent and long-lasting anti-secretory effect on hydrogen/potassium-ATPase because of its high level of accumulation and slow clearance from gastric tissue [11] [12]. The acid-inhibitory effects of VPZ are much more potent than those of PPIs; therefore, it can be expected to be more effective when used for $H$. pylori eradication. A double-blind phase 3 study of triple therapy with VPZ for first-line $H$. pylori eradication showed a high success rate of $92.6 \%$ [13]. However, this study merely verified the non-inferiority of VPZ to lansoprazole (LPZ). Other studies also reported that $H$. pylori eradication rates for 7-day $\mathrm{P}$-CAB-based triple therapies were more effective than those of PPI-based triple therapies; however, these were retrospective studies with small sample sizes [14]-[24]. Recently, meta-analyses [25] and prospective studies [26] [27] showed that the eradication rate of first-line VPZ therapy was higher than that with PPI therapy.

The aim of this study was to evaluate the efficacy and tolerability of triple therapy with VPZ in comparison to 7-day PPI-based low-dose CAM triple therapy in previously untreated patients, with a large sample size and using a propensity score matching analysis. We also investigated factors that increased the eradication rate using VPZ. 


\section{Materials and Methods}

\subsection{Ethics}

This study was conducted in accordance with the Declaration of Helsinki. The institutional review board of Yamanashi Koseiren Health Care Center approved the study protocol (27-014).

\subsection{Study Participants}

This was a retrospective, single institution study. We reviewed the medical records of patients who underwent esophago-gastro-duodenoscopy screening as part of a general medical checkup program, who were infected with $H$. pylori, and who received $H$. pylori eradication therapy from January 2012 to May 2016 at Yamanashi Koseiren Health Care Center. All patients were $\geq 20$ years of age. In addition to age, exclusion criteria were: 1) consumption of antibiotics, nonsteroid anti-inflammatory drugs, antithrombotic agents, PPIs, or supplementation with probiotics; 2) allergy to antibiotics or PPIs, 3) previous gastric surgery; 4) severe concomitant cardiopulmonary disease or serious hepatic/renal dysfunction or malignancy; and 5) pregnancy or lactation. Patients who had received treatment for $H$. pylori eradication in the past were excluded.

Of the 4213 consecutive patients who received $H$. pylori first-line eradication therapy, 40 who received the eradication therapies after stomach surgery, 44 who had received supplementation with probiotics, and 11 who were prescribed antibiotics or a PPI were excluded. As a result, 4118 patients were enrolled in this study; 1286 patients who received VPZ therapy were compared to 2832 patients who received PPI therapy (Figure 1).

\subsection{H. pylori Eradication}

The presence of $H$. pylori was confirmed before treatment by one or more of the following methods: the rapid urease test (PyloriTek; Serim Research Corp., Elkhart, IN, USA), ${ }^{13} \mathrm{C}$-urea breath test (UBIT $100 \mathrm{mg}$ tablet/POCone; Otsuka Pharmaceutical Co., Tokyo, Japan) $\geq 2.5 \%$, and/or the anti- $H$. pylori immunoglobulin serological test (LZ H. pylori Antibody; Eiken Chemical Co., Tokyo, Japan) $>20 \mathrm{U} / \mathrm{ml}$. The normal value specified by the manufacturer of this antibody test is $<10 \mathrm{U} / \mathrm{ml}$; however, serologic examination is also considered positive in those with a past history of $H$. pylori infection. The antibody titer after eradication therapy was reported to be up to $20 \mathrm{U} / \mathrm{ml}$ [28]; therefore, in this study, patients with an antibody titer of $>20 \mathrm{U} / \mathrm{ml}$ were considered as currently infected with $H$. pylori.

Previously untreated patients were administered first-line VPZ therapy or PPI therapy. The type of eradication therapy depended on the date of therapy; all patients treated before November 2013 received PPI therapy with LPZ and those treated from November 2013 to February 2015 received eradication therapy using LPZ or rabeprazole (RPZ); there was no previous determination of whether a patient received LPZ or RPZ. Then from March 2015, all patients were treated 


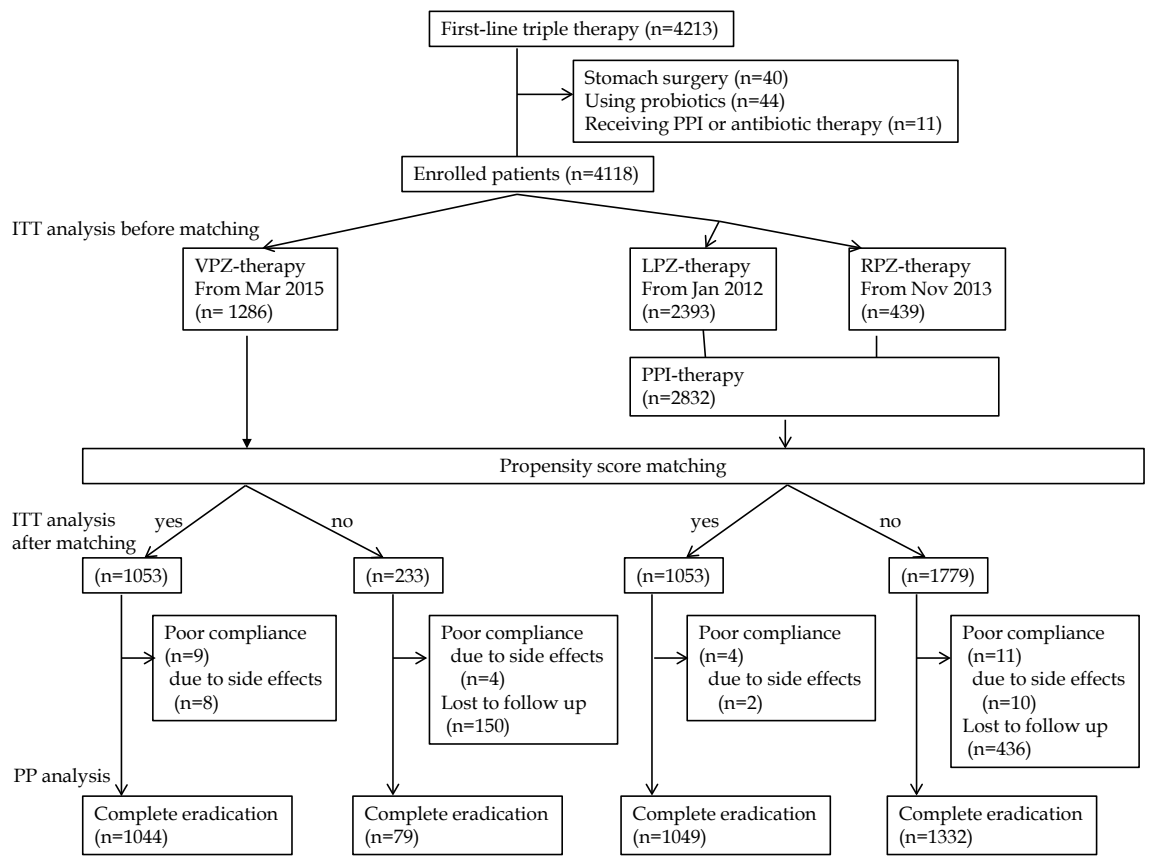

Figure 1. Study flow chart. A, first-line eradication therapy for Helicobacter pylori; B, second-line eradication therapy for $H$. pylori. ITT, intention-to-treat; LPZ, lansoprazole; $\mathrm{PP}$, per-protocol; PPI, proton pump inhibitor; RPZ, rabeprazole; VPZ, vonoprazan.

with VPZ therapy. VPZ therapy was comprised of $40 \mathrm{mg}$ VPZ + $1500 \mathrm{mg}$ AMPC + $400 \mathrm{mg}$ CAM, all twice a day for 7 days; the entire dosage regimen was contained in one package. The PPI therapy was comprised of $60 \mathrm{mg}$ LPZ (Lansap 400; Takeda Pharmaceutical Co., Tokyo, Japan) or 20 mg RPZ (Rabecure Pack 400; Eisai, Tokyo, Japan) + 1500 mg AMPC + 400 mg CAM, all given twice a day for 7 days.

Treatment duration and antibiotic dosages were determined according to the approved indication in Japan for first-line and second-line H. pylori eradication. We instructed all patients not to smoke during the eradication treatment.

Patients were requested to come to the Center again at least 8 weeks after the treatment period to evaluate their $H$. pylori status, to confirm compliance during therapy, and to identify possible side effects. $H$. pylori eradication was assessed by the [13] C-urea breath test with success defined as a result of $<2.5 \%$.

\subsection{Endoscopic Findings}

All patients underwent esophago-gastro-duodenoscopy. Diseases associated with H. pylori infection were diagnosed by endoscopic findings. The definition of atrophic gastritis was diagnosed as closed type-2 (C-2) or higher by the classification of Kimura and Takemoto [29].

\subsection{Procedures}

The primary outcome in this study was the first-line $H$. pylori eradication rates for VPZ and PPI therapy before and after propensity score matching. We used 
intention-to-treat (ITT) and per-protocol (PP) analysis in the assessment of eradication efficacy. All enrolled patients who started medication were included in the ITT analysis regardless of mistakes in medication or compliance (Figure 1). In the PP analysis, patients were included who achieved complete eradication and underwent the follow-up ${ }^{13} \mathrm{C}$-urea breath test. The secondary outcomes in this study were to study factors related to the $H$. pylori eradication rates in firstline VPZ therapy and to assess the adverse-event rates related to the first-line eradication therapy.

\subsection{Statistical Analysis}

We compared continuous variables in the univariate analysis with the test and presented arithmetic means and standard deviations. Categorical variables were analyzed with the chi-square test. Univariate and multivariate logistic regressions were used to assess the effect of VPZ therapy. The propensity score was determined by multivariable logistic regression analysis. $\mathrm{P}$ values less than 0.05 were considered statistically significant.

Because of non-random assignment to various treatments the result may be biased estimates. In recent years, the use of propensity scores has become increasingly popular for the correction of variables that may confound an association [14] [30]. Several covariates are combined into one variable, the propensity score. The propensity score is estimated by multivariate logistic regression, which is performed with the assignment of therapy as the objective variable and other covariates as explanatory variables. The available covariates in this study were age (y), gender (male/female), body mass index (BMI), endoscopic findings, smoking, and drinking alcohol [8] [31]. The appropriateness of this model was estimated by the receiver operating characteristic curve (ROC), and the area under the curve (AUC) of the ROC may indicate predictive power. The AUC of first-line VPZ therapy was 0.70 . The model calculated the expected probability or propensity score of each patient assigned to VPZ therapy.

Patients who underwent each therapy were nearest-neighbor matched within caliper width, which was equal to one quarter of the standard deviation of the logit of the propensity score, and were selected for one-to-one pair matching. The matched cohort was evaluated for differences between treatment groups in each of the potential confounding factors after adjustment for any residual differences.

All analyses were performed using JMP 12.1 software (SAS Institute, Cary, NC).

\section{Results}

\subsection{Baseline Characteristics of Patients Undergoing First-Line Therapy (Table 1)}

The average age differed significantly between groups receiving first-line therapy (VPZ vs. PPI, p < 0.0001); ages were $57.9 \pm 11.3 \mathrm{y}$ with VPZ and $60.1 \pm 10.7 \mathrm{y}$ 
with PPIs. The male ratios were 52.3\% with VPZ therapy and 51.5\% with PPI therapy. Endoscopic findings were comprised of no abnormality, duodenal ulcer, atrophic gastritis, gastric ulcer, and post-endoscopic mucosal resection for early gastric cancer and were confirmed as 3.0\%, 0.8\%, 93.2\%, 3.0\% and $0.1 \%$, respectively, in the VPZ therapy group (VPZ vs. PPI, $\mathrm{p}<0.0001$ ). Atrophic gastritis constituted the largest proportion of abnormal findings in the VPZ therapy group. There were no significant differences in BMI among groups. Smokers constituted $15.0 \%$ of the VPZ therapy group and $12.3 \%$ of the PPI therapy group (VPZ vs. PPI, $\mathrm{p}=0.033$ ). Consumers of alcohol constituted $48.5 \%$ of the VPZ therapy group and $47.2 \%$ of the PPI therapy recipients.

\subsection{Eradication Rate of First-Line Therapy}

Successful first-line eradication rates according to ITT analysis and PP analysis, respectively, were $79.8 \%$ (95\% confidence interval (CI), 77.5\% - 81.9\%) and 91.4\% (95\% CI, 89.6\% - 92.9\%) for VPZ therapy and 66.3\% (95\% CI, 64.6\% $68.0 \%)$ and $78.9 \%$ (95\% CI, 77.2\% - 80.5\%) for PPI therapy. The eradication rate for first-line VPZ therapy was better than that of PPI therapy $(\mathrm{p}<.0001)$.

In the group receiving PPI therapy, successful first-line eradication rates according to ITT analysis and PP analysis, respectively, were 66.3\% (95\% CI 64.4\% - $68.1 \%$ ) and $79.3 \%$ (95\% CI, $77.5 \%$ - 81.0\%) for LPZ therapy and $66.5 \%$ (95\% CI, $62.0 \%-70.8 \%)$ and $76.6 \%$ (95\% CI, $72.1-80.6)$ for RPZ therapy. First-line VPZ therapy was significantly superior to first-line therapy with LPZ or RPZ (p $<.0001)$. There was no significant difference in the eradication rates between LPZ and RPZ in both ITT and PP analysis (Table 1).

\subsection{Eradication Rates for First-Line Therapy According to Patients' Age and Years of Administration (Figure 2)}

Differences in the eradication rates according to medication timing and the age of patients who completed the therapies were examined. First-line VPZ therapy had the highest eradication rates among all age groups. In those $<40$ years old, successful first-line eradication rates according to PP analysis were 85.7\% (95\% CI, 74.6\% - 92.6\%) for VPZ therapy and 71.7\% (95\% CI, 61.8\% 79.9\%) for PPI therapy indicating no statistical differences between the two groups $(\mathrm{p}=0.05)$. In all other age groups, the first-line therapy using VPZ was superior to that of PPIs. There was no significant difference in eradication rate in each age group according to different administration periods of LPZ.

\subsection{Baseline Characteristics of Propensity-Matched Patients} (Table 2)

Propensity score matching was performed for the entire population. The 1053 patients who had VPZ therapy and 1053 patients who had a PPI therapy were nearest-neighbor matched within a caliper width of 0.0086 . After propensity matching, all the people who lost to follow up were excluded. Eradication rates for first-line VPZ therapy were 91.3\% (95\% CI, 89.4\% - 92.8\%) in ITT analysis 


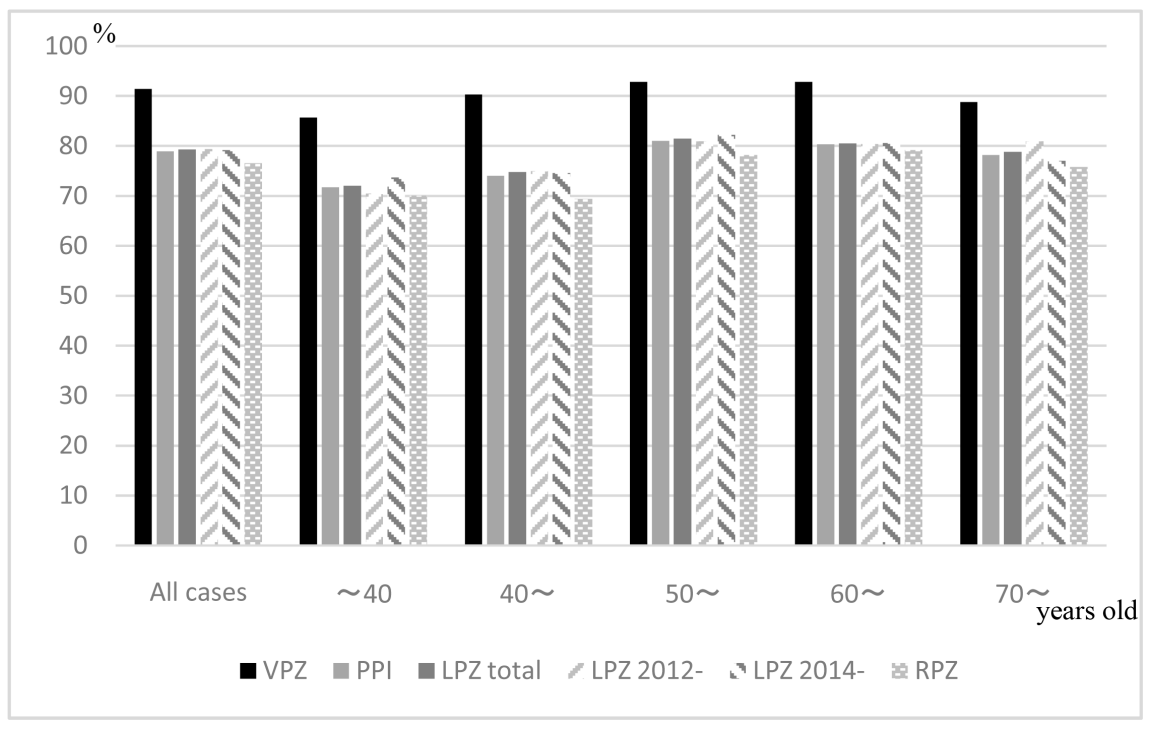

Figure 2. Eradication rate of first-line therapy according to patients' age, years of administration Differences in the rate of first-line eradication therapy for $H$. pylori according to medication timing and the age of patients who completed the therapies were examined. First-line VPZ therapy had the highest eradication rate in all age groups. In those $<40$ years old, successful first-line eradication rates according to per-protocol analysis were no statistical differences between VPZ therapy and PPI therapy. In all other age groups, the first-line therapy using VPZ was superior to that of PPIs. There was no significant difference in eradication rate in each age group at different administration periods of LPZ. VPZ, vonoprazan; PPI, proton pump inhibitor (lansoprazole+rabeprazole); LPZ, lansoprazole; RPZ, rabeprazole; NS, not significant.

and $92.1 \%$ (95\% CI, $90.3 \%$ - 93.5\%) in PP analysis. The eradication rates for first-line PPI therapy were $79.4 \%$ (95\% CI, 76.8\% - 81.7\%) in ITT analysis and 79.7\% (95\% CI, 77.2\% - 82.0\%) in PP analysis. Both analyses after matching also showed a significant difference between VPZ therapy and PPI therapy $(\mathrm{p}<$ 0.0001).

\subsection{Factors Related to H. pylori Eradication Rates for 7-Day VPZ-Based Low-Dose CAM Triple Therapy}

Age, gender, BMI, endoscopic findings, smoking, and drinking alcohol have been reported to be factors related to the success of $H$. pylori eradication therapy (Table 3). On univariate analysis, age $>45$ years (odds ratio $1.70,95 \% \mathrm{CI}, 1.04$ 2.78) and gastric mucosal atrophy (odds ratio $2.70,95 \%$ CI 1.21 - 6.03) were associated with treatment success. The multivariate analysis confirmed that gastric mucosal atrophy (odds ratio 2.51, 95\% CI 1.12 - 5.63) was independently associated with treatment success. In this study, smoking did not affect the eradication rate, since before treatment there had been an intervention that provided non-smoking guidance.

\subsection{Adverse Events and Compliance}

Table 4 shows adverse events and their incidences in each group. In first-line 
Table 1. Baseline characteristics of the patients who received the first-line eradication therapy for Helicobacter pylori.

\begin{tabular}{|c|c|c|c|c|c|c|c|c|}
\hline & VPZ & PPI & LPZ & $\mathrm{RPZ}$ & & & value & \\
\hline & A & B & c & d & A vs. $B$ & A vs. c & A vs. d & c vs. d \\
\hline No. of patients enrolled & 1286 & 2832 & 2393 & 439 & & & & \\
\hline Completed the therapy & 1123 & 2381 & 2000 & 381 & & & & \\
\hline Age (Years) & $57.9 \pm 11.3$ & $60.1 \pm 10.7$ & $60.0 \pm 10.7$ & $61.0 \pm 10.8$ & $<.0001$ & $<.0001$ & $<.0001$ & 0.083 \\
\hline Range & $24-86$ & $26-88$ & $26-88$ & $30-84$ & & & & \\
\hline Gender & & & & & 0.613 & 0.994 & 0.050 & 0.038 \\
\hline Male & 673 & 1458 & 1252 & 206 & & & & \\
\hline Female & 613 & 1374 & 1141 & 233 & & & & \\
\hline $\mathrm{BMI}\left(\mathrm{kg} / \mathrm{m}^{2}\right)$ & $22.8 \pm 3.1$ & $22.6 \pm 3.1$ & $22.6 \pm 3.1$ & $22.5 \pm 3.1$ & 0.120 & 0.203 & 0.081 & 0.305 \\
\hline Range & $14.7-42.0$ & $14.3-46$. & $14.3-46.0$ & $15.4-36.7$ & & & & \\
\hline Endoscopic findings & & & & & $<.0001$ & $<.0001$ & 0.038 & 0.524 \\
\hline No abnormality & 38 & 23 & 19 & 4 & & & & \\
\hline Duodenal ulcer & 10 & 56 & 48 & 8 & & & & \\
\hline Atrophic gastritis & 1199 & 2586 & 2181 & 405 & & & & \\
\hline Gastric ulcer & 38 & 165 & 145 & 20 & & & & \\
\hline After ER for GC & 1 & 2 & 0 & 2 & & & & \\
\hline Smoking (yes) & 189 & 348 & 303 & 45 & 0.033 & 0.084 & 0.019 & 0.157 \\
\hline Drinking (yes) & 624 & 1336 & 1140 & 196 & 0.422 & 0.609 & 0.160 & 0.248 \\
\hline Successful eradication ${ }^{*}$ & 1026 & 1878 & 1586 & 292 & & & & \\
\hline $\begin{array}{l}\text { ITT analysis \% } \\
(95 \% \mathrm{CI})\end{array}$ & $\begin{array}{c}79.8 \\
(77.5-81.9)\end{array}$ & $\begin{array}{c}66.3 \\
(64.6-68.0)\end{array}$ & $\begin{array}{c}66.3 \\
(64.4-68.1)\end{array}$ & $\begin{array}{c}66.5 \\
(62.0-70.8)\end{array}$ & $<.0001$ & $<.0001$ & $<.0001$ & 0.874 \\
\hline $\begin{array}{l}\text { PP analysis \% } \\
\text { (95\%CI) }\end{array}$ & $\begin{array}{c}91.4 \\
(89.6-92.9)\end{array}$ & $\begin{array}{c}78.9 \\
(77.2-80.5)\end{array}$ & $\begin{array}{c}79.3 \\
(77.5-81.0)\end{array}$ & $\begin{array}{c}76.6 \\
(72.1-80.6)\end{array}$ & $<.0001$ & $<.0001$ & $<.0001$ & 0.244 \\
\hline Adverse events & 51 & 104 & 78 & 26 & 0.647 & 0.267 & 0.087 & 0.006 \\
\hline
\end{tabular}

*, H. pylori eradication was assessed by the ${ }^{13} \mathrm{C}$-urea breath test with success defined as a result of $<2.5 \%$. VPZ, vonoprazan; PPI, proton pump inhibitor (lansoprazole+rabeprazole); LPZ, lansoprazole; RPZ, rabeprazole; BMI, body mass index; ER, endoscopic mucosal resection; GC, gastric cancer; ITT, intention-to-treat; PP, per-protocol; CI, confidence interval.

therapy, the overall adverse event rate for VPZ therapy $(4.0 \%, 51 / 1286)$ was the same as for PPI therapy (Table 1) (3.3\% for LPZ therapy and 5.9\% for RPZ therapy). The adverse event with the highest incidence was skin rash in each group $(1.2 \%-2.7 \%)$ and the second most common was diarrhea in all groups $(1.1 \%-2.1 \%)$. All adverse events were less than grade 3 (Common Terminology Criteria for Adverse Event Version 4.0). Some cases of skin rash required medical treatment, while other events resolved spontaneously without treatment. $H$. pylori eradication therapy using VPZ was interrupted in 1 patient with vomiting, 4 with diarrhea, and 3 with skin rash (0.5\%) (Figure 1). Although it was outside the period of this study, we experienced one case with onset of Stevens-Johnson syndrome with first-line VPZ therapy. 
Table 2. Baseline Characteristics of the propensity matched patients who received firstline eradication therapy for Helicobacter pylori.

\begin{tabular}{|c|c|c|c|}
\hline & VPZ & PPI & $p$ value \\
\hline No. of patients enrolled & 1053 & 1053 & \\
\hline Completed the therapy & 1044 & 1049 & \\
\hline Age (Years) & $58.9 \pm 10.8$ & $59.0 \pm 10.7$ & 0.843 \\
\hline Gender & & & 0.459 \\
\hline Male & 531 & 514 & \\
\hline Female & 522 & 539 & \\
\hline BMI $\left(\mathrm{kg} / \mathrm{m}^{2}\right)$ & $22.7 \pm 3.0$ & $22.6 \pm 3.0$ & 0.399 \\
\hline Endoscopic findings & & & 0.730 \\
\hline No abnormality & 4 & 3 & \\
\hline Duodenal ulcer & 8 & 8 & \\
\hline Atrophic gastritis & 1012 & 1017 & \\
\hline Gastric ulcer & 29 & 25 & \\
\hline Smoking (yes) & 126 & 129 & 0.841 \\
\hline Drinking (yes) & 490 & 505 & 0.513 \\
\hline Logic of the propensity score & $-0.49 \pm 0.28$ & $-0.49 \pm 0.28$ & 0.997 \\
\hline Successful eradication & 961 & 836 & \\
\hline ITT analysis* \% (95\% CI) & $91.3(89.4-92.8)$ & $79.4(76.8-81.7)$ & $<.0001$ \\
\hline $\mathrm{PP}$ analysis $\%(95 \% \mathrm{CI})$ & $92.1(90.3-93.5)$ & $79.7(77.2-82.0)$ & $<.0001$ \\
\hline Adverse events & 46 & 45 & 0.915 \\
\hline
\end{tabular}

Caliper width $=0.0086 ;{ }^{*}$, After propensity matching, all the people who lost to follow up were excluded. VPZ, vonoprazan; PPI, proton pump inhibitor (lansoprazole + rabeprazole); BMI, body mass index; ITT, intention-to-treat; PP, per-protocol; CI, confidence interval.

\section{Discussion}

The first-line eradication rate of $H$. pylori with VPZ therapy was found to be $79.8 \%$ in the ITT analysis and $91.4 \%$ in the PP analysis, which was significantly higher than those rates with PPI therapy. Each study group was comprised of 1000 or more individuals. Adverse events did not differ between the VPZ and PPI groups.

Several studies have investigated the efficacy of first-line eradication of $H$. $p y$ lori with VPZ therapy, and successful eradication rates using VPZ were $62.3 \%$ $95.8 \%$ by ITT analysis and $81.7 \%-95.7 \%$ by PP analysis [13]-[27]. In our study of a large sample, the eradication rate for VPZ therapy was significantly higher than that with PPI therapy in $H$. pylori-positive patients.

Since this study only involved gastric acid inhibitors, the results would be limited to this class of medications. The acid-inhibitory effect of VPZ was greater than that of the PPIs [11] [12] [32]. The CYP2C19 genotype was shown to influence the inhibitory effects of PPIs on gastric acids [31]. Serum concentrations of esomeprazole (EPZ) and RPZ were less affected by the CYP2C19 polymorphism, 
Table 3. Factors affecting first-line vonoprazan therapy for Helicobacter pylori.

\begin{tabular}{|c|c|c|c|c|c|c|}
\hline \multirow{2}{*}{ variables } & \multirow{2}{*}{ total } & \multirow{2}{*}{$\begin{array}{l}\text { Successful } \\
\text { eradication } \\
(\%)\end{array}$} & \multicolumn{2}{|c|}{ Univariate analysis } & \multicolumn{2}{|c|}{ Multivariate analysis } \\
\hline & & & $\begin{array}{c}\text { Odds ratio } \\
(95 \% \text { CI })\end{array}$ & $\begin{array}{c}p \\
\text { value }\end{array}$ & $\begin{array}{c}\text { Odds ratio } \\
(95 \% \text { CI) }\end{array}$ & $\begin{array}{c}p \\
\text { value }\end{array}$ \\
\hline Total number & 1123 & $1026(91.4)$ & & & & \\
\hline \multicolumn{7}{|l|}{ Age (Years) } \\
\hline$\leqq 45$ & 190 & $166(87.4)$ & 1 & 0.033 & 1 & \multirow{2}{*}{0.053} \\
\hline$>45$ & 933 & $860(92.2)$ & $1.70(1.04-2.78)$ & & $1.62(0.99-2.67)$ & \\
\hline \multicolumn{7}{|l|}{ Gender } \\
\hline Female & 543 & $495(91.2)$ & 1 & 0.816 & & \\
\hline Male & 580 & $531(91.6)$ & $1.05(0.69-1.59)$ & & & \\
\hline \multicolumn{7}{|l|}{ BMI } \\
\hline$<25$ & 871 & $793(91.0)$ & 1 & 0.482 & & \\
\hline$\geqq 25$ & 252 & $233(92.5)$ & $1.21(0.72-2.03)$ & & & \\
\hline \multicolumn{7}{|l|}{ Endoscopic findings } \\
\hline Without atrophy & 41 & $33(80.5)$ & 1 & 0.015 & 1 & 0.026 \\
\hline With atrophy & 1082 & $993(91.8)$ & $2.70(1.21-6.03)$ & & $2.51(1.12-5.63)$ & \\
\hline \multicolumn{7}{|l|}{ Smoking } \\
\hline no & 976 & $889(91.1)$ & 1 & 0.397 & & \\
\hline yes & 147 & $137(93.2)$ & $1.34(0.68-2.64)$ & & & \\
\hline \multicolumn{7}{|l|}{ Drinking } \\
\hline yes & 532 & $480(90.2)$ & 1 & 0.199 & & \\
\hline no & 591 & $546(92.4)$ & $1.31(0.87-2.00)$. & & & \\
\hline
\end{tabular}

BMI, body mass index; CI, confidence interval.

with the result that their acid inhibition was effective against the extensive metabolizer genotype [31] [33]. The rate of successful first-line eradication with VPZ therapy was superior to that with RPZ therapy [18] [19] [20] [21] or therapy with EPZ [20] [21] [22].

The main role of gastric acid-inhibitory agents in $H$. pylori eradication therapy is to increase the bioavailability and stability of antibacterial agents in the stomach [34]. In patients who achieved successful eradication with LPZ therapy, the median 24-hour $\mathrm{pH}$ was 6.4 (range 5.0 - 7.6), which was higher than that in patients without eradication ( $\mathrm{pH} 5.2,2.2-6.2$ ), and the median percentage time of a $\mathrm{pH}<4.0$ during the 24 -hour post-dose period in patients with eradication (0.5\%) was significantly shorter than that in patients without eradication (26.7\%) [35]. AMPC has poor stability, particularly at a low $\mathrm{pH}$, but nevertheless has a half-life of over 15 hours at $\mathrm{pH}$ 2. CAM is the most acid labile, having a half-life of less than 1 hour at $\mathrm{pH}$ 2. AMPC and CAM are easily degraded in acidic conditions. In addition, $H$. pylori regains its replicative capability at a $\mathrm{pH}>6$, so that it is more susceptible to antibiotics in this environment [36]. AMPC has an anti-bacterial effect over a $\mathrm{pH}$ range of approximately 5.5 to 7.5 , and the sensitivity 
Table 4. Adverse events in first-line therapy using vonoprazan.

\begin{tabular}{cccc}
\hline & VPZ & LPZ & RPZ \\
\hline $\mathrm{n}$ & 1286 & 2393 & 439 \\
Skin rash (\%) & $24(1.9)$ & $29(1.2)$ & $12(2.7)$ \\
Diarrhea (\%) & $23(1.8)$ & $27(1.1)$ & $9(2.1)$ \\
Nausea, Vomiting (\%) & $2(0.2)$ & $7(0.3)$ & 0 \\
Abdominal pain (\%) & $1(0.1)$ & $3(0.1)$ & 0 \\
Constipation (\%) & $1(0.1)$ & $5(0.2)$ & $2(0.5)$ \\
Dysgeusia (\%) & $1(0.1)$ & $4(0.2)$ & $1(0.2)$ \\
Fever (\%) & 0 & $1(0.0)$ & $1(0.2)$ \\
Stomatitis (\%) & 0 & $2(0.1)$ & $2(0.5)$ \\
Abdominal fullness (\%) & 0 & $1(0.0)$ & 0 \\
$\star$ Other & 1 & 6 & 0 \\
Total (\%) & $51(4.0)$ & $78(3.3)$ & $26(5.9)$ \\
\hline
\end{tabular}

*Other: including loss of appetite, increased bowel sound, languor, numbness of tongue, stomach upset, uncomfortable feeling, candida vaginitis. VPZ, vonoprazan; LPZ, lansoprazole; RPZ, rabeprazole.

of $H$. pylori to AMPC is 8.3 to 20 times greater, respectively, at $\mathrm{pH} 7.5$ than at $\mathrm{pH} 5.5$ [34]. Likewise, the sensitivity of $H$. pylori to CAM is 160 times greater at $\mathrm{pH} 7.5$ than at $\mathrm{pH}$ 5.5. From the point of view of the sensitivity of H. pylori, the high acid-inhibitory effect of VPZ can be assumed to be the main factor in the high eradication rate with first-line VPZ therapy.

The eradication rates with standard PPI triple therapy have declined below $80 \%$, as observed in some of the latest studies because of increasing drug resistance, mostly to CAM [8] [9]. It was reported that the eradication rate for CAM-resistant strains of $H$. pylori was significantly higher using VPZ treatment than PPI treatment [13] [15] [17]. The high acid suppression with VPZ may have an enhancing effect in patients with CAM-resistant strains. Patients with CAM-resistant strains at each degree of minimum inhibitory concentration (MIC) could achieve eradication [37].

Two agents, VPZ and AMPC, might be the most responsible for the effect of triple therapy. In fact, when the role of high-dose dual therapy (HDDT) with 20 mg RPZ and $750 \mathrm{mg}$ AMPC 4 times per day for 14 days was examined, ITT analysis showed that $H$. pylori was eradicated in $95.3 \%$ of patients in the HDDT group and $81 \%$ in the standard triple therapy group [38]. Conversely, a study of the effect of extended dual release LPZ with AMPC had to be discontinued because of a lack of efficacy (53.8\% in both ITT and PP analysis) [39]. It was reported that dual therapy with VPZ and AMPC achieved a 95\% eradication rate; however, it was not significantly more effective than PPI therapy [40]. Other first-line $H$. pylori eradication regimens include hybrid therapy [41], sequential therapy, and concomitant therapy (93.3\%, $96.6 \%$ and $94.0 \%$ eradication by PP analysis, respectively) [9] [10]. There were no significant trends in adverse events for these therapies. In consensus reports [2] [3], in areas of high (>15\%) 
CAM resistance, bismuth quadruple or non-bismuth quadruple concomitant therapy was recommended. No studies have compared these directly with first-line VPZ therapy. Each therapy has a success rate of $90 \%$ or greater, so there may not be a difference in comparison with VPZ therapy in terms of efficacy. Since a long dosing period and high dosing frequency clinically would lead to a decrease in compliance, it would be reasonable to conclude that there is an advantage to first-line VPZ therapy.

What factors weaken the effect of first-line VPZ therapy should be addressed. Sue et al. [27] reported that CAM resistance had a significant impact on eradication failure of first-line VPZ therapy. First-line VPZ therapy could overcome CAM-resistant strains and increased the eradication rate [13] [15] [17]. However, there were circumstances that could not be attributed to the CAM-resistant strains. As with CYP2C19 in PPI, CYP3A4/5, which is a main factor in the metabolism of VPZ, might affect the rate of eradication using VPZ [42]. In multivariate analyses in our study, the absence of gastric mucosal atrophy was the independent factor that lowered the rate of eradication of $H$. pylori. That is, even if VPZ were used, it might be impossible to achieve gastric acid suppression at $\mathrm{pH}>6$, which is necessary for eradication, for a long time. In a phase 1 trial of VPZ, the 24-h pH $\geq 5$ holding time ratio (HTR) increased dose dependently, with mean maximum effects after a $120 \mathrm{mg}$ dose in Japan (93\%) and a $40 \mathrm{mg}$ dose in the UK (70\%) [12]. Nighttime acid suppression also increased in a dose-dependent manner. Among Japanese 99\% had a pH $\geq 5$ HTR during 12 - $24 \mathrm{~h}$ after the $40 \mathrm{mg}$ dose compared to $79 \%$ in the UK overnight (from 20:00 to 08:00) [12]. Therefore, some patients undergoing first-line eradication therapy with VPZ might not maintain a $\mathrm{pH}>6$ in the stomach, and this might lead to eradication failure.

The presence of AMPC-resistant strains also makes eradication of $H$. pylori difficult. The resistance rate of $\mathrm{H}$. pylori to AMPC was very low, but the rate of AMPC insensitivity was $16.9 \%-17.5 \%$ [43]. The antimicrobial action of AMPC depends on the ratio between dosing interval and time over MIC (\% Time-above MIC). For an AMPC insensitive strain, the shortening of \% Time-above MIC due to an increase in the MIC is the cause of failure to eradicate $H$. pylori [44]. The stability of AMPC by gastric acid suppression, which was the effect of VPZ, may improve.

This study has some limitations, including those inherent in the retrospective study design. In addition, this was a single-institution study and included only Japanese patients. We did not consider CAM resistance and the CYP2C19 polymorphism, which have been reported to be major factors related to the success of $H$. pylori eradication therapy. In conclusion, 7-day low-dose CAM triple therapy using VPZ was more effective as first-line H. pylori eradication therapy than 7-day low-dose CAM standard triple therapy and was generally well tolerated. For the first time, we showed that the absence of gastric atrophy represented a weakness in the eradication of H. pylori using VPZ. Even in a state without gastric mucosal atrophy, it is necessary that the eradication rate is further increased and that stronger acid suppression is achieved with VPZ. 


\section{Supportive Foundations}

None.

\section{Disclosure}

The authors have no conflicts of interest to disclose.

\section{References}

[1] Suerbaum, S. and Michetti, P. (2002) Helicobacter pylori Infection. The New England Journal of Medicine, 347, 1175-1186. https://doi.org/10.1056/NEJMra020542

[2] Malfertheiner, P., Megraud, F., O’Morain, C.A., Gisbert, J.P., Kuipers, E.J., Axon, A.T., Bazzoli, F., Gasbarrini, A., Atherton, J., Graham, D.Y., Hunt, R., Moayyedi, P., Rokkas, T., Rugge, M., Selgrad, M., Suerbaum, S., Sugano, K. and El-Omar, E.M. (2017) European Helicobacter and Microbiota Study Group and Consensus panel.Management of Helicobacter pylori Infection-The Maastricht V/Florence Consensus Report. Gut, 66, 6-30. https://doi.org/10.1136/gutjnl-2016-312288

[3] Fallone, C.A., Chiba, N., van Zanten, S.V., Fischbach, L., Gisbert, J.P., Hunt, R.H., Jones, N.L., Render, C., Leontiadis, G.I., Moayyedi, P. and Marshall, J.K. (2016) The Toronto Consensus for the Treatment of Helicobacter pylori Infection in Adults. Gastroenterology, 151, 51-69. https://doi.org/10.1053/j.gastro.2016.04.006

[4] World Health Organization (2014) H. pylori Eradication as a Strategy for Preventing Gastric Cancer.

http://www.iarc.fr/en/publications/pdfs-online/wrk/wrk8/Helicobacter_pylori_Erad ication.pdf

[5] Kusano, C., Gotoda, T., Ishikawa, H. and Moriyama, M. (2017) The Administrative Project of Helicobacter pylori Infection Screening among Junior High School Students in an Area of Japan with a High Incidence of Gastric Cancer. Gastric Cancer, 20, 16-19.

[6] Wang, B., Lv, Z.F., Wang, Y.H., Wang, H., Liu, X.Q., Xie, Y. and Zhou, X.J. (2014) Standard Triple Therapy for Helicobacter pylori Infection in China: A Meta-Analysis. World Journal of Gastroenterology, 20, 14973-14985. https://doi.org/10.3748/wjg.v20.i40.14973

[7] Graham, D.Y. and Fischbach, L. (2010) Helicobacter pylori Treatment in the Era of Increasing Antibiotic Resistance. Gut, 59, 1143-1153. https://doi.org/10.1136/gut.2009.192757

[8] Zhang, M. (2015) High Antibiotic Resistance Rate: A Difficult Issue for Helicobacter pylori Eradication Treatment. World Journal of Gastroenterology, 21, 1343213437. https://doi.org/10.3748/wjg.v21.i48.13432

[9] Jung, S.M., Cheung, D.Y., Kim, J.I., Kim, I. and Seong, H. (2016) Comparing the Efficacy of Concomitant Therapy with Sequential Therapy as the First-Line Therapy of Helicobacter pylori Eradication. Gastroenterology Research and Practice, 2016, Article ID: 1293649. https://doi.org/10.1155/2016/1293649

[10] Tepeš, B., Vujasinović, M., Šeruga, M., Stefanovič, M., Forte, A. and Jeverica, S. (2016) Randomized Clinical Trial Comparing 10-Day Sequential, 7-Day Concomitant and 7-Day Standard Triple Therapies for Helicobacter pylori Eradication. European Journal of Gastroenterology \& Hepatology, 28, 676-683. https://doi.org/10.1097/MEG.0000000000000590

[11] Hori, Y., Imanishi, A., Matsukawa, J., Tsukimi, Y., Nishida, H., Arikawa, Y., Hirase, K., Kajino, M. and Inatomi, N. (2010) 1-[5-(2-Fluorophenyl)-1-(pyridine 
3-ylsulfonyl)-1H-pyrrol-3-yl]-N-methylmethanamine monofumarate (TAK-438), a Novel and Potent Potassium-Competitive Acid Blocker for the Treatment of Acid-Related Diseases. Journal of Pharmacology and Experimental Therapeutics, 335, 231-238. https://doi.org/10.1124/jpet.110.170274

[12] Sakurai, Y., Nishimura, A., Kennedy, G., Hibberd, M., Jenkins, R., Okamoto, H., Yoneyama, T., Jenkins, H., Ashida, K., Irie, S. and Täubel, J. (2015) Safety, Tolerability, Pharmacokinetics, and Pharmacodynamics of Single Rising TAK-438 (Vonoprazan) Doses in Healthy Male Japanese/Non-Japanese Subjects. Clinical and Translational Gastroenterology, 6, e94. https://doi.org/10.1038/ctg.2015.18

[13] Murakami, K., Sakurai, Y., Shiino, M., Funao, N., Nishimura, A. and Asaka, M. (2016) Vonoprazan, a Novel Potassium-Competitive Acid Blocker, as a Component of First-Line and Second-Line Triple Therapy for Helicobacter pylori Eradication: A Phase III, Randomised, Double-Blind Study. Gut, 65, 1439-1446. https://doi.org/10.1136/gutjnl-2015-311304

[14] Suzuki, S., Gotoda, T., Kusano, C., Iwatsuka, K. and Moriyama, M. (2016) The Efficacy and Tolerability of a Triple Therapy Containing a Potassium-Competitive Acid Blocker Compared with a 7-Day PPI-Based Low-Dose Clarithromycin Triple Therapy. The American Journal of Gastroenterology, 111, 949-956.

https://doi.org/10.1038/ajg.2016.182

[15] Matsumoto, H., Shiotani, A., Katsumata, R., Fujita, M., Nakato, R., Murao, T., Ishii, M., Kamada, T., Haruma, K. and Graham, D.Y. (2016) Helicobacter pylori Eradication with Proton Pump Inhibitors or Potassium-Competitive Acid Blockers: The Effect of Clarithromycin Resistance. Digestive Diseases and Sciences, 61, 3215-3220. https://doi.org/10.1007/s10620-016-4305-0

[16] Yamada, S., Kawakami, T., Nakatsugawa, Y., Suzuki, T., Fujii, H., Tomatsuri, N., Nakamura, H., Sato, H., Okuyama, Y., Kimura, H. and Yoshida, N. (2016) Usefulness of Vonoprazan, a Potassium Ion-Competitive Acid Blocker, for Primary Eradication of Helicobacter pylori. World Journal of Gastrointestinal Pharmacology and Therapeutics, 7, 550-555. https://doi.org/10.4292/wjgpt.v7.i4.550

[17] Noda, H., Noguchi, S., Yoshimine, T., Goji, S., Adachi, K., Tamura, Y., Izawa, S., Ebi, M., Yamamoto, S., Ogasawara, N., Funaki, Y., Sasaki, M. and Kasugai, K. (2016) A Novel Potassium-Competitive Acid Blocker Improves the Efficacy of Clarithromycin-Containing 7-Day Triple Therapy against Helicobacter pylori. Journal of Gastrointestinal and Liver Diseases, 25, 283-288.

[18] Kajihara, Y., Shimoyama, T. and Mizuki, I. (2017) Analysis of the Cost-Effectiveness of Using Vonoprazan-Amoxicillin-Clarithromycin Triple Therapy for First-Line Helicobacter pylori Eradication. Scandinavian Journal of Gastroenterology, 52, 238-241. https://doi.org/10.1080/00365521.2016.1250157

[19] Shinozaki, S., Nomoto, H., Kondo, Y., Sakamoto, H., Hayashi, Y., Yamamoto, H., Lefor, A.K. and Osawa, H. (2016) Comparison of Vonoprazan and Proton Pump Inhibitors for Eradication of Helicobacter pylori. The Kaohsiung Journal of Medical Sciences, 32, 255-260.

[20] Shichijo, S., Hirata, Y., Niikura, R., Hayakawa, Y., Yamada, A., Mochizuki, S., Matsuo, K., Isomura, Y., Seto, M., Suzuki, N., Suzuki, H., Yamamoto, S., Sugimoto, T., Omae, T., Okamoto, M., Watabe, H., Togo, G., Takano, N., Fukui, K., Ito, Y. and Koike, K. (2016) Vonoprazan versus Conventional Proton Pump Inhibitor-Based Triple Therapy as First-Line Treatment against Helicobacter pylori: A Multicenter Retrospective Study in Clinical Practice. Journal of Digestive Diseases, 17, 670-675. https://doi.org/10.1111/1751-2980.12398 
[21] Sakurai, K., Suda, H., Ido, Y., Takeichi, T., Okuda, A., Hasuda, K. and Hattori, M. (2017) Comparative Study: Vonoprazan and Proton Pump Inhibitors in Helicobacter pylori Eradication Therapy. World Journal of Gastroenterology, 23, 668-675. https://doi.org/10.3748/wjg.v23.i4.668

[22] Tsujimae, M., Yamashita, H., Hashimura, H., Kano, C., Shimoyama, K., Kanamori, A., Matsumoto, K., Koizumi, A., Momose, K., Eguchi, T., Fukuchi, T., Fujita, M. and Okada, A. (2016) A Comparative Study of a New Class of Gastric Acid Suppressant Agent Named Vonoparazan versus Esomeprazole for the Eradication of Helicobacter pylori. Digestion, 94, 240-246. https://doi.org/10.1159/000454762

[23] Nishizawa, T., Suzuki, H., Fujimoto, A., Kinoshita, H., Yoshida, S., Isomura, Y., Toyoshima, A., Kanai, T., Yahagi, N. and Toyoshima, O. (2017) Effects of Patient Age and Choice of Antisecretory Agent on Success of Eradication Therapy for Helicobacter pylori Infection. Journal of Clinical Biochemistry and Nutrition, 60, 208-210. https://doi.org/10.3164/jcbn.16-86

[24] Tanabe, H., Ando, K., Sato, K., Ito, T., Goto, M., Sato, T., Fujinaga, A., Kawamoto, T., Utsumi, T., Yanagawa, N., Ichiishi, E., Otake, T., Kohgo, Y., Nomura, Y., Ueno, N., Sugano, H., Kashima, S., Moriichi, K., Fujiya, M. and Okumura, T. (2017) Efficacy of Vonoprazan-Based Triple Therapy for Helicobacter pylori Eradication: A Multicenter Study and a Review of the Literature. Digestive Diseases and Sciences. https://doi.org/10.1007/s10620-017-4664-1

[25] Jung, Y.S., Kim, E.H. and Park, C.H. (2017) Systematic Review with Meta-Analysis: The Efficacy of Vonoprazan-Based Triple Therapy on Helicobacter pylori Eradication. Alimentary Pharmacology \& Therapeutics, 46, 106-114. https://doi.org/10.1111/apt.14130

[26] Maruyama, M., Tanaka, N., Kubota, D., Miyajima, M., Kimura, T., Tokutake, K., Imai, R., Fujisawa, T., Mori, H., Matsuda, Y., Wada, S., Horiuchi, A. and Kiyosawa, K. (2017) Vonoprazan-Based Regimen Is More Useful than PPI-Based One as a First-Line Helicobacter pylori Eradication: A Randomized Controlled Trial. Canadian Journal of Gastroenterology and Hepatology. https://doi.org/10.1155/2017/4385161

[27] Sue, S., Kuwashima, H., Iwata, Y., Oka, H., Arima, I., Fukuchi, T., Sanga, K., Inokuchi, Y., Ishii, Y., Kanno, M., Terada, M., Amano, H., Naito, M., Iwase, S., Okazaki, H., Komatsu, K., Kokawa, A., Kawana, I., Morimoto, M., Saito, T., Kunishi, Y., Ikeda, A., Takahashi, D., Miwa, H., Sasaki, T., Tamura, T., Kondo, M., Shibata, W. and Maeda, S. (2017) The Superiority of Vonoprazan-Based First-Line Triple Therapy with Clarithromycin: A Prospective Multi-Center Cohort Study on Helicobacter pylori Eradication. Internal Medicine, 56, 1277-1285. https://doi.org/10.2169/internalmedicine.56.7833

[28] Aoyama, N., Shigeta, S. and Yokozaki, H. (2017) Comparison of H. pylori Antibody between E-Plate (ELISA) and Latex Agglutination Method (LATEX) among Strictly Diagnosed H. pylori Infection Status. Japanese Journal of Helicobacter Research, 18, 4-11.

[29] Kimura, K. and Takemoto, T. (1969) An Endoscopic Recognition of the Atrophic Border and Its Significance in Chronic Gastritis. Endoscopy, 1, 87-97.

https://doi.org/10.1055/s-0028-1098086

[30] Lindenauer, P.K., Pekow, P., Wang, K., Mamidi, D.K., Gutierrez, B. and Benjamin, E.M. (2005) Perioperative Beta-Blocker Therapy and Mortality after Major Noncardiac Surgery. The New England Journal of Medicine, 353, 349-361.

https://doi.org/10.1056/NEJMoa041895 
[31] Lee, J.Y., Kim, N., Kim, M.S., Choi, Y.J., Lee, J.W., Yoon, H., Shin, C.M., Park, Y.S., Lee, D.H. and Jung, H.C. (2014) Factors Affecting First-Line Triple Therapy of $\mathrm{He}-$ licobacter pylori Including CYP2C19 Genotype and Antibiotic Resistance. Digestive Diseases and Sciences, 59, 1235-1243. https://doi.org/10.1007/s10620-014-3093-7

[32] Jenkins, H., Sakurai, Y., Nishimura, A., Okamoto, H., Hibberd, M., Jenkins, R., Yoneyama, T., Ashida, K., Ogama, Y. and Warrington, S. (2015) Randomised Clinical Trial: Safety, Tolerability, Pharmacokinetics and Pharmacodynamics of Repeated Doses of TAK-438 (Vonoprazan), a Novel Potassium-Competitive Acid Blocker, in Healthy Male Subjects. Alimentary Pharmacology \& Therapeutics, 41, 636-648. https://doi.org/10.1111/apt.13121

[33] Adachi, K., Katsube, T., Kawamura, A., Takashima, T., Yuki, M., Amano, K., Ishihara, S., Fukuda, R., Watanabe, M. and Kinoshita, Y. (2000) CYP2C19 Genotype Status and Intragastric $\mathrm{pH}$ during Dosing with Lansoprazole or Rabeprazole. Alimentary Pharmacology \& Therapeutics, 14, 1259-1266. https://doi.org/10.1046/j.1365-2036.2000.00840.x

[34] Labenz, J. (2001) Current Role of Acid Suppressants in Helicobacter pylori Eradication Therapy. Best Practice \& Research: Clinical Gastroenterology, 15, 413-431. https://doi.org/10.1053/bega.2001.0188

[35] Sugimoto, M., Furuta, T., Shirai, N., Kodaira, C., Nishino, M., Ikuma, M., Ishizaki, T. and Hishida, A. (2007) Evidence That the Degree and Duration of Acid Suppression Are Related to Helicobacter pylori Eradication by Triple Therapy. Helicobacter, 12, 317-323. https://doi.org/10.1111/j.1523-5378.2007.00508.x

[36] Sachs, G., Scott, D.R. and Wen, Y. (2011) Gastric Infection by Helicobacter pylori. Current Gastroenterology Reports, 13, 540-546. https://doi.org/10.1007/s11894-011-0226-4

[37] Nakajima, T. (2016) Vonoprazan Efficacy for First-Line Treatment of Helicobacter pylori Infection-Evaluation of Drug-Susceptibility Breakpoint. Japanese Journal of Helicobacter Research, 18, 53-60.

[38] Yang, J.C., Lin, C.J., Wang, H.L., Chen, J.D., Kao, J.Y., Shun, C.T., Lu, C.W., Lin, B.R., Shieh, M.J., Chang, M.C., Chang, Y.T., Wei, S.C., Lin, L.C., Yeh, W.C., Kuo, J.S., Tung, C.C., Leong, Y.L., Wang, T.H. and Wong, J.M. (2015) High-Dose Dual Therapy Is Superior to Standard First-Line or Rescue Therapy for Helicobacter pylori Infection. Clinical Gastroenterology and Hepatology, 13, 895-905.

[39] Attumi, T.A. and Graham, D.Y. (2014) High-Dose Extended-Release Lansoprazole (Dexlansoprazole) and Amoxicillin Dual Therapy for Helicobacter pylori Infections. Helicobacter, 19, 319-322. https://doi.org/10.1111/hel.12126

[40] Furuta, T., Sahara, S., Ichikawa, H., Kagami, T., Uotani, T., Yamade, M., Sugimoto, M., Hamaya, Y., Iwaizumi, M., Osawa, S. and Sugimoto, K. (2016) Dual Therapy with Vonoprazan and Amoxicillin Is as Effective as Standard PPI-Based Triple Therapy with Amoxicillin and Clarithromycin or Metronidazole in Japan. Gastroenterology, 150, S877.

[41] Hsu, P.I., Lin, P.C. and Graham, D.Y. (2014) Hybrid Therapy for Helicobacter pylori Infection: A Systemic Review and Meta-Analysis. World Journal of Gastroenterology, 19, 319-322.

[42] Sugimoto, M., Ban, H., Hira, D., Kamiya, T., Otsuka, T., Inatomi, O., Bamba, S., Terada, T. and Andoh, A. (2017) Letter: CYP3A4/5 Genotype Status and Outcome of Vonoprazan-Containing Helicobacter pylori Eradication Therapy in Japan. Alimentary Pharmacology \& Therapeutics, 45, 1009-1010.

https://doi.org/10.1111/apt.13959 
[43] Hashinaga, M., Okimoto, T., Kodama, M., Mizukami, K., Ogawa, R., Okamoto, K., Shuto, M., Fukuda, K., Sonoda, H., Fukuda, M., Honda, S., Yamaoka, Y. and Murakami, K. (2016) わが国における薬剂耐性 Helicobacter pylori の現状-2013-2014 年度耐性菌サーベイランスの集計報告. [Current Status of Drug Resistance Helicobacter Pylori in Japan-Total Report of Resistant Bacterial Surveillance for 2013 to 2014.] Japanese Journal of Helicobacter Research, 45-49. (In Japanese)

[44] Furuta, T., Sugimoto, M., Yamade, M., Uotani, T., Sahara, S., Ichikawa, H., Yamada, T., Osawa, S., Sugimoto, K., Watanabe, H. and Umemura, K. (2014) Effect of Dosing Schemes of Amoxicillin on Eradication Rates of Helicobacter pylori with Amoxicillin-Based Triple Therapy. The Journal of Clinical Pharmacology, 54, 258-266. https://doi.org/10.1002/jcph.195

Submit or recommend next manuscript to SCIRP and we will provide best service for you:

Accepting pre-submission inquiries through Email, Facebook, LinkedIn, Twitter, etc. A wide selection of journals (inclusive of 9 subjects, more than 200 journals) Providing 24-hour high-quality service

User-friendly online submission system

Fair and swift peer-review system

Efficient typesetting and proofreading procedure

Display of the result of downloads and visits, as well as the number of cited articles Maximum dissemination of your research work

Submit your manuscript at: http://papersubmission.scirp.org/

Or contact ojgas@scirp.org 